\title{
Steady state numerical model for critical two-phase flow in a nozzle
}

\author{
S. Martel ${ }^{1}$, Y. Mercadier ${ }^{1} \&$ M. Dostie ${ }^{2}$ \\ ${ }^{I}$ Department of Mechanical Engineering, Université de Sherbrooke, \\ Canada \\ ${ }^{2}$ Laboratoire des technologies de l'énergie, Hydro-Québec, Shawinigan, \\ Canada
}

\begin{abstract}
This paper presents a steady state two-phase flow model including new choking criteria for one-dimensional conservative systems. As a first step, this model is used to study the flow in the motive nozzle of an ejector. Mechanical disequilibria and momentum exchange between phases are taken into account and the numerical scheme uses the SIMPLE algorithm. Numerical results are compared to experimental and previous numerical results from the literature. Keywords: critical two-phase flow, critical location, steady state model.
\end{abstract}

\section{Introduction}

The steady state flow of compressible fluid through convergent-divergent nozzles covers various important flow phenomena like the occurrence of critical flow conditions, transition from subsonic to supersonic flow or the occurrence of flow discontinuities. One phenomena still of interest is the choking condition in a critical flow such as in supersonic ejectors. Supersonic ejectors are widely used in a range of applications such as aerospace, propulsion, refrigeration and many thermal systems. In this paper, a one-dimensional compressible steady state twophase flow model is presented with new choking criterions that are directly related to optimal flux conditions developed by [1]. As a first step, this model is used to study the flow in the motive nozzle of an ejector. 


\section{Numerical model}

This is a one-dimensional two-fluid single pressure model using one temperature and mechanical disequilibria between phases in which no phase changes occurred. The procedure used for the calculation of the flow field is the standard SIMPLE algorithm developed for steady state flow conditions [2]. A constant liquid density and perfect gas law for compressible component are assumed. In addition, droplets in gas flow for momentum exchange between phases are assumed to be uniform and with constant diameter. In order to take account of the mechanical disequilibria, the slip ratio between phases must be obtained using drag source term.

With these assumptions, the following four equations model is obtained:

$$
\begin{aligned}
& \frac{\partial}{\partial x} \sum_{k}\left(f_{M k}\right) a_{s} \alpha_{1} \rho_{1} u_{1}=0 \\
& \frac{\partial}{\partial x} \sum_{k}\left(f_{M k} s_{k}\right) a_{s} \alpha_{1} \rho_{1} u_{1}^{2}+\frac{d}{d x}\left(a_{s} p\right)=p \frac{\partial a_{s}}{\partial x} \\
& \frac{\partial}{\partial x}\left[A \alpha_{1} \rho_{1} u_{1}\left(\sum_{k}\left(f_{M k} s_{k}^{2}\right) \frac{u_{1}^{2}}{2}+\sum_{k}\left(f_{M k} f_{T k}\right) \frac{C_{p 1} P}{R_{1} \rho_{1}}\right)\right]=0 \\
& \frac{\partial}{\partial x}\left(A \alpha_{2} \rho_{2} u_{2}^{2}\right)+\frac{\partial}{\partial x}\left(a_{s} \alpha_{2} p\right)=\Gamma_{2, J}+\Gamma_{2, J}^{c}
\end{aligned}
$$

where $\Gamma_{2, J}$ is the drag force between phases and $\Gamma_{2}^{c}{ }_{J}$ is the force cause by the variable section:

$$
\begin{gathered}
\Gamma_{2, J}=-\frac{V_{2}}{V_{p}} \frac{A_{2}^{D}}{\Delta x} \frac{C_{D}}{2} \rho_{1}\left(u_{2}-u_{1}\right)\left|u_{2}-u_{1}\right| \\
\Gamma_{2, J}^{c}=p \frac{\partial}{\partial x}\left(a_{s} \alpha_{2}\right)
\end{gathered}
$$

In these equations, $S_{k}$ is the slip ratio, $f_{M k}$ the mass flow ratio, and $\mathrm{f}_{T \mathrm{k}}$ enthalpy ratio of phase $k$. These ratios can be respectively defined by:

$$
\begin{gathered}
s_{k}=\frac{u_{k}}{u_{1}} \\
f_{M k}=\frac{a_{k} \rho_{k} u_{k}}{a_{1} \rho_{1} u_{1}} \\
f_{T k}=\frac{C p_{k} T_{k}}{C p_{1} T_{1}}
\end{gathered}
$$

In the previous equations, $a_{s}$ is the sectional area, $\alpha_{k}$ the volumetric fraction of each phase $k, \rho_{k}$ the density of each phase, $u_{k}$ the velocity of each phase, $p$ the 
flow pressure, $C_{p I}$ the heat capacity of compressible phase, and $R_{I}$ the specific gas constant of compressible phase. For compressible phase, $k$ is 1 and for incompressible phase, $k$ equal 2 . Volumetric fraction and geometrical section are linked by the following equations representing a global constraint that all phases must occupy the total nozzle section:

$$
\begin{aligned}
& \alpha_{k}=\frac{a_{k}}{a_{s}} \\
& \sum_{k} \alpha_{k}=1
\end{aligned}
$$

\section{Validation}

At the inlet of the nozzle, homogeneous equilibrium flow is assumed from reservoir. For this reason, each phase have the same temperature and pressure. The inlet volume fraction is imposed. For the outlet boundary condition a constant exit pressure is applied. The initial conditions in the nozzle are identical with the upstream reservoir conditions which imply that the transient calculation starts with a strong discontinuity at the nozzle exit. The model has been validated with experimental data from Elliot and Weinberg [3] and with Carofano and McManus [4]. Finally, results have been compared to numerical results from Städtke [5].

\subsection{Elliot and Weinberg comparison}

Experimental results were obtained using a $1.27 \mathrm{~m}$ experimental nozzle. Authors show one pressure profile and a table resuming experimental results obtained for different mass flow ratio such as mass flow rate, exit velocity, and thrust measurement. Inlet conditions for all tests are $p_{0}=10.3421(\mathrm{MPa}), T_{0}=293 \mathrm{~K}$ and an exit pressure of $0.1013 \mathrm{MPa}$. The Figure 1 shows that numerical pressure

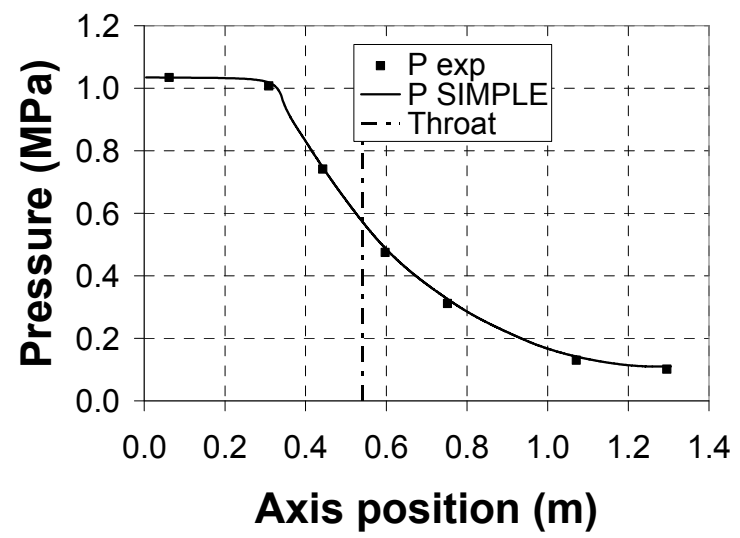

Figure 1: $\quad$ Pressure profile in the nozzle. 
profile is in good agreement with experimental results. For this test, mass flow ratio is 39.1 and experimental mass flow rate is $67.33 \mathrm{~kg} / \mathrm{s}$. The numerical mass flow rate obtained is 67.64 which give an error of $0.45 \%$.

Table 1 shows comparison between numerical and experimental results for mass flow ratio range of 15.3 - 64.9. For all tests, results are in good agreement for mass flow rate since error varies from 0.11 to $2.77 \%$. However, comparison of experimental and numerical thrust results give an overestimation in all cases between 4.96 to $8.28 \%$. From Elliot and Weinberg numerical results, the difference between wall frictionless flow velocity and the velocity with friction is about $5.6 \%$. From this observation, the wall frictionless flow assumption resulting in a higher mean velocity used in the calculation of the thrust is the cause of this overestimation.

Table 1: $\quad$ Comparison with results of Elliot and Weinberg.

\begin{tabular}{c|c|c|c|c|c|c|c|c|c}
\hline \hline \multicolumn{7}{c|}{ Experimental results } & \multicolumn{5}{c}{ Numerical results } \\
\hline $\begin{array}{c}\text { Mass } \\
\text { flow } \\
\text { ratio }\end{array}$ & $\begin{array}{c}\mathrm{M} \\
(\mathrm{kg} / \mathrm{s})\end{array}$ & $\begin{array}{c}\text { Exit } \\
\text { velocity } \\
(\mathrm{m} / \mathrm{s})\end{array}$ & $\begin{array}{c}\text { Thrust } \\
(\mathrm{N})\end{array}$ & $\begin{array}{c}\mathrm{M} \\
(\mathrm{kg} / \mathrm{s})\end{array}$ & $\begin{array}{c}\text { Error } \\
(\%)\end{array}$ & $\begin{array}{c}\text { Exit } \\
\text { velocity } \\
(\mathrm{m} / \mathrm{s})\end{array}$ & $\begin{array}{c}\text { Error } \\
(\%)\end{array}$ & $\begin{array}{c}\text { Thrust } \\
(\mathrm{N})\end{array}$ & $\begin{array}{c}\text { Error } \\
(\%)\end{array}$ \\
\hline \hline 15.3 & 44.5 & 143 & 6334 & 45.8 & 2.77 & 147 & 3.35 & 6748 & 6.54 \\
\hline 17.2 & 47.7 & 131 & 6236 & 48.1 & 0.83 & 140 & 7.07 & 6753 & 8.28 \\
\hline 21.1 & 51.8 & 125 & 6441 & 52.5 & 1.27 & 129 & 3.34 & 6760 & 4.96 \\
\hline 22.3 & 53.6 & 118 & 6308 & 53.7 & 0.14 & 126 & 6.73 & 6762 & 7.21 \\
\hline 28.3 & 57.7 & 109 & 6308 & 59.3 & 2.76 & 114 & 4.34 & 6773 & 7.38 \\
\hline 30.1 & 60.9 & 104 & 6334 & 60.8 & 0.11 & 111 & 6.83 & 6776 & 6.97 \\
\hline 39.1 & 67.7 & 94 & 6334 & 67.3 & 0.59 & 100 & 7.30 & 6760 & 6.72 \\
\hline 51.6 & 74.5 & 85 & 6334 & 75.4 & 1.13 & 90 & 6.27 & 6813 & 7.55 \\
\hline 64.9 & 81.4 & 78 & 6334 & 82.2 & 1.00 & 83 & 6.73 & 6844 & 8.04 \\
\hline \hline
\end{tabular}

\subsection{Carofano and McManus comparison}

The nozzle used by Carofano and McManus [4] to obtain experimental twophase flow results is used to validate numerical results. They obtain a pressure profile for $p_{0}=0.3440 \mathrm{MPa}, T_{0}=289 \mathrm{~K}$ and an exit pressure of $0.1455 \mathrm{MPa}$. The mass flow ratio used in this case is 0.1013 . The experimental mass flow rate is $0.4141 \mathrm{~kg} / \mathrm{s}$ and the numerical mass flow rate obtained is 0.4103 which implies a difference under $1 \%$. The pressure profile is in good agreement with experimental.

\subsection{Städtke comparison}

The ASTAR nozzle geometry presented by Städtke [5] is used to compare numerical results. For this case, fixed upstream reservoir pressure and temperature of $p_{0}=1 \mathrm{MPa}, T_{0}=400 \mathrm{~K}, u_{1}=u_{2}$ is used with a mass flow rate 
ratio $\left(F_{M k}\right)$ of unity and an exit pressure of $0.6 \mathrm{MPa}$. Numerical results obtained with this scheme are in good agreement with those of [5] as shown on Figure 1.2. Total mass flow rate obtained by [5] is $5.68 \mathrm{~kg} / \mathrm{s}$ compared to $5.70 \mathrm{~kg} / \mathrm{s}$ obtained with this model which implied a difference of $0.35 \%$. It is interesting to see that the numerical scheme is able to capture choc wave in the nozzle. The differences between velocity profiles can be explained by the fact that no information about the droplet assumptions are given by Städtke. Droplet diameter and drag correlation have a direct effect on the slip ratio and the velocity profiles. In addition, Städtke are using a two temperatures model giving some differences in the phase velocity results.

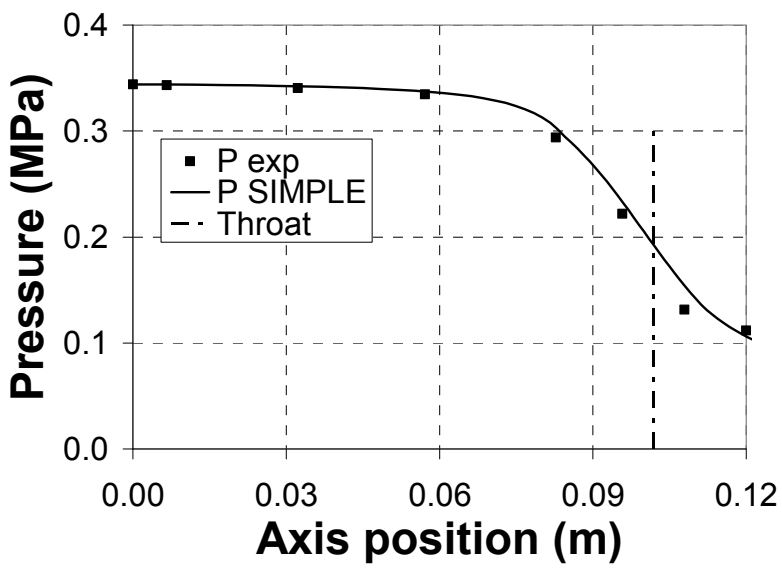

Figure 2: $\quad$ Pressure profile in the nozzle.

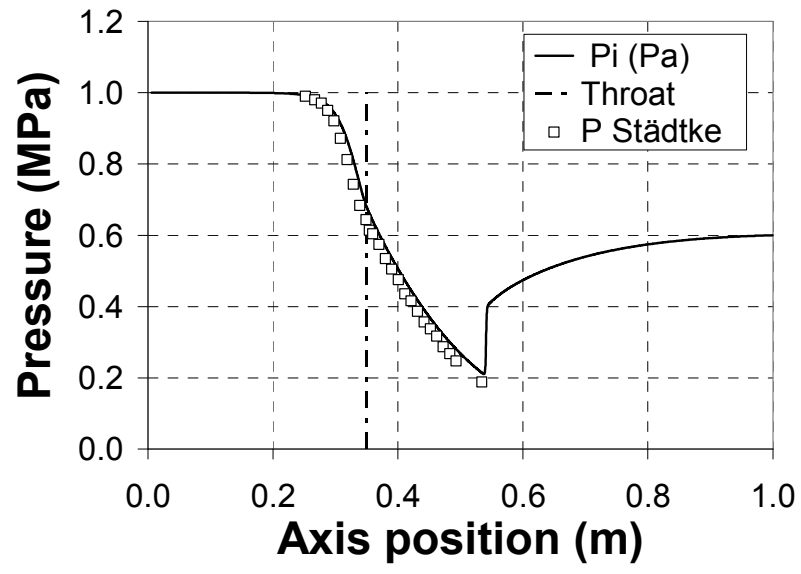

Figure 3: $\quad$ Pressure profiles in the ASTAR nozzle. 


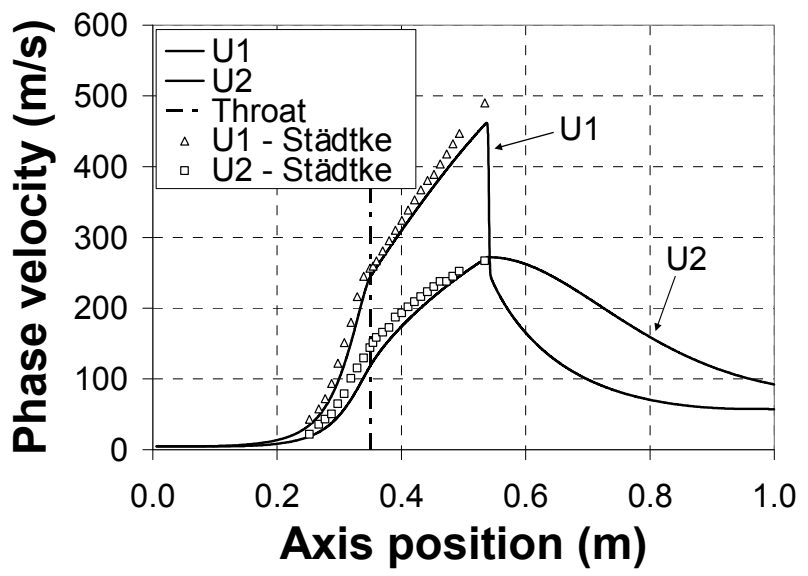

Figure 4: Velocity profiles in the ASTAR nozzle.

\section{Conclusions}

Multiphase systems present significant scientific challenges and the choking phenomenon has to be taken into account properly to achieve an accurate model of two phase flow. More results are obtained concerning super-critical behavior in comparison with mono-phase compressible flow. This numerical scheme give good results and the numerical study have given a lot of information about critical two-phase flow behavior. It also shows that steady state models are achievable for critical two-phase flow. Such an approach is in some cases simpler that using transient models which involve much more complex propagation phenomenon. This model allows a good range of inlet void fraction from droplet flow (void fraction close to 1) to bubble flow (void fraction close to 0.4 ). Numerical results also validate the fact that critical location is not necessary at the throat section. For variable slip ratio, this is not necessary the case since mass, momentum and energy exchanges between phases give a different behavior and critical location appear after the throat. Numerical study and theoretical consideration are into progress to predict critical position and effect of mass flow ratio and thermical disequilibria on flow behavior.

\section{Acknowledgements}

The work described here was supported by NSERC, FQRNT and NSERC Chair in Industrial Energy Efficiency (chairholder: N. Galanis) at Université de Sherbrooke with the support of Hydro-Quebec (Energy Technology Laboratory, LTE), Rio Tinto Alcan and the CANMET Energy Technology Center (CETCVarennes, Natural Resources Canada). 


\section{References}

[1] Dostie M., Mercadier Y., Critical fluxes in conservative systems: application to multiphase flow. Submitted to Journal of Fluid Mechanics, 2011.

[2] Patankar, S.V. (1980). Numerical heat transfer and fluid flow, Hemisphere Publishing Corporation, New-York, 197 p.

[3] Elliot, D. G. and Weinberg, E. Acceleration of Liquids in Two-Phase Nozzles, JPL Tech. Rep. 32-987, 1968.

[4] Carofano, G. C. and McManus, H. N. (1969). An analytical and experimental study of the flow of air-water and steam-water mixtures in a converging-diverging nozzle, Progress in Heat and Mass Transfer, Vol. 2, Pergamon Press, Oxford.

[5] Städtke, H. Gasdynamic Aspects of Two-Phase Flow. WILEY-VCH, Weinheim, 273 p, 2006. 